\title{
STRATEGIC ENTREPRENEURSHIP DALAM PENINGKATKAN VOLUME PENJUALAN EKSPOR KENDANG "DJEMBE" PADA UD. BUDI LUHUR, KOTA BLITAR
}

\author{
Indria Guntarayana \\ Fakultas Ilmu Sosial Dan Ilmu Politik, Universitas Islam Balitar \\ Email : indriaguntarayana@unisbablitar.ac.id
}

\begin{abstract}
ABSRACT
Djembe is an icon of Blitar City, this is because the largest djembe handicraft industry center is in Blitar City. UD. Budi Luhur in Blitar City, East Java is one of the SMEs in the wood craft industry. UD. Budi Luhur is an UKM that moves to market its djembe products by exporting to foreign countries. The purpose of this study was to describe how the entrepreneurial strategy of UD. Budi Luhur in entering and marketing its products on the international market. This study also explains the application of entrepreneurial strategies to UD. Budi Luhur in increasing the export sales volume of kendang djembe handicrafts, as well as alternatives to maintain the entrepreneurial strategy that has been applied by UD. Budi Luhur in dealing with international markets. The research method used in this study was descriptive with a qualitative approach. The data sources in this study are primary data by conducting interviews with the owners of UD. Budi Luhur and the Regional Cooperative and SME Office, Blitar City and focus group discussion (FGD) together with the Tanggung Village Bubut Kayu Association which is a working partner of UD. Budi Luhur and secondary data in the form of documents related to the theme of this research. The results showed that exports were chosen by UD. Budi Luhur to enter the international market. UD. Budi Luhur applies growth, innovation, network, harvest / exit strategies by reading opportunities to develop markets, innovating products, creating good relationships with buyers and being able to form profitable networks and working with similar companies to meet market demand so as to maximize sales and increase the volume of export sales.
\end{abstract}

\section{Keywords: Entrepreneurship Strategy, Innovation, Network Success}

\section{PENDAHULUAN}

Perusahaan yang bergerak dalam bidang kerajinan banyak yang memilih ekspor sebagai strategi dalam penjualan, karena dengan ekspor, pangsa pasar dapat meluas ke negara-negara yang memiliki perbedaan dalam sumber daya alam untuk menghasilkan produk sejenis yang dapat menjadi keunggulan bagi pengusaha eksportir. Alasan banyaknya pengusaha kerajinan memilih untuk mengekspor produk ke luar negeri karena pertimbangan peluang pasar luar negeri lebih besar. Seperti yang disampaikan oleh Kotler dan Keller (2009:316) "Salah 
satu faktor perusahaan lebih memilih beroperasi di pasar luar negeri yaitu karena pasar internasional memberikan peluang laba yang lebih tinggi dibandingkan pasar domestik".

Keanekaragaman sektor kerajinan di Indonesia ditunjang dengan produk unggulan dari setiap provinsi di Indonesia yang masing-masing memiliki ciri khas yang berbeda. Provinsi Jawa Timur merupakan salah satu provinsi dari 33 provinsi di Indonesia dan merupakan provinsi yang kaya dengan sumber daya alam, potensi sumber daya alam meliputi berbagai sektor, perindustrian, kerajinan, pertanian, peternakan, perikanan, perkebunan, kehutanan, dan kelautan serta pariwisata.

Data mengenai realisasi ekspor Provinsi jawa Timur yang menunjukkan selisih volume ekspor yang sangat signifikan antara sektor migas dan non migas. Kerajinan kriya/handycraft adalah kerajinan yang menggunakan tangan sebagai alat dasar pembuatannya dan memiliki manfaat dalam kehidupan sehari-hari sebagai benda pakai, benda hias dan benda mainan dengan nilai seni pada setiap produknya. Seni kerajinan kriya cenderung dipengaruhi oleh budaya, alam dan adat daerah setempat, sehingga setiap produk kriya dari setiap daerah memiliki keunikan dan keindahan yang berbeda. Seni kriya meliputi seni kerajinan kulit, logam, anyaman, kerajinan kayu atau ukir kayu, batik, dan keramik. Salah satu jenis kerajinan kayu adalah kendang djembe.

Kendang djembe merupakan alat musik tradisional yang paling diminati oleh kebanyakan musisi Indonesia maupun mancanegara. Bahan yang digunakan dalam pembuatan kendang djembe umumnya menggunakan bahan dasar kayu. Untuk kayu yang digunakan ada beberapa jenis kayu. Kayu mahoni dan kayu nangka. Proses pembuatan kendang djembe tidaklah mudah. Untuk membuatnya diperlukan tahapan-tahapan yang memerlukan kesabaran keuletan serta memiliki talenta yang berjiwa seni. Kendang djembe tidak hanya dibuat dengan mesin saja. Untuk menciptakan karya yang unik dan menarik, kendang djembe diberikan berbagai sentuhan kesenian tangan. Seperti motif, pernak pernik dan berbagai jenis ukiran sebagai daya tarik bagi pembeli. UD. Budi Luhur karena UKM ini merupakan satu-satunya UKM penghasil djembe di Kota Blitar yang telah 
mendapatkan penghargaan PARAMAKARYA dari Kementrian Ketenagakerjaan pada tahun 2013

TABEL 1 : Total Penjualan Djembe ke China Sumber:

Data Penjualan UD Budi Luhur 2014-2017,

\begin{tabular}{|l|c|c|c|c|}
\hline \multirow{2}{*}{ Produk } & \multicolumn{4}{|c|}{ Tahun } \\
\cline { 2 - 5 } & $\mathbf{2 0 1 4}$ & $\mathbf{2 0 1 5}$ & $\mathbf{2 0 1 6}$ & $\mathbf{2 0 1 7}$ \\
\hline Diembe 40 & 3.250 & 5.500 & 6.070 & 9.054 \\
\hline Diembe 50 & 4.170 & 6.750 & 8.805 & 14.070 \\
\hline Diembe 60 & 4.580 & 19.800 & 9.775 & 40.870 \\
\hline Total (Unit) & $\mathbf{1 2 . 0 0 0}$ & $\mathbf{1 9 . 8 0 0}$ & $\mathbf{2 4 . 6 5 0}$ & $\mathbf{4 0 . 8 0 0}$ \\
\hline
\end{tabular}

Data diolah (2018)

Tabel 1 menjelaskan tentang volume penjualan ekspor pada UD. Budi Luhur ke China dimana bulan Agustus, Oktober, Desember 2016 dan Juni, Oktober 2017 mengalami kenaikan volume penjualan dan hanya mengalami sedikit penurunan volume penjualan pada bulan Juni 2016 dan Februari 2017. China merupakan negara tujuan ekspor UD. Budi Luhur dengan total penjualan produk tertinggi dibandingkan negara tujuan ekspor lainnya. Sebuah produk UKM tidak akan sampai ke tangan konsumen tanpa adanya kegiatan pemasaran dan strategi kewirausahaan (strategic entrepreneurship) khusus bagi pelaku UKM.

Ketatnya persaingan global mengharuskan perusahaan menciptakan strategi khusus bagi pelaku UKM untuk menaikan volume penjualan ekspor. Strategi pemasaran pagi pelaku UKM berperan untuk menjaga pertumbuhan bisnis dalam jangka panjang. Strategi pemasaran harus ditinjau dan dikembangkan sesuai dengan perkembangan pasar dan lingkungan. Strategi pemasaran khususnya bagi pelaku UKM harus memberikan gambaran yang jelas dan terarah tentang apa yang akan dilakukan perusahaan dalam menggunakan setiap kesempatan pada suatu pasar.

\section{METODE PENELITIAN}

Metode penelitian yang digunakan dalam penelitian ini adalah deskriptif dengan pendekatan kualitatif dikarenakan masalah yang akan diteliti oleh peneliti bersifat tidak pasti atau sementara dan akan berkembang setelah peneliti berada di lapangan untuk menggambarkan semua data atau keadaan subjek/objek penelitian 
(seseorang, lembaga, masyarakat dan lain- lain) yang kemudian dianalisis dengan realita yang ada untuk selanjutnya dapat ditemukan pemecahan masalahnya (Widi, 2010:84).

Metode Analisis Data Analisis data dalam penelitian kualitatif dimulai dengan menyiapkan dan mengorganisasikan data untuk analisis, kemudian mereduksi data tersebut menjadi tema, dan terakhir menyajikan data dalam bentuk bagan, tabel, atau pembahasan (Creswell, 2015:251). Sesuai dengan penelitian ini yang merupakan penelitian kualitatif studi kasus, maka peneliti menggunakan empat analisis menurut Creswell (2015:253) yaitu: 1. Membuat sketsa ide dengan menyoroti informasi tertentu dalam deskripsi, 2. Mereduksi kode menjadi tema dengan mengidentifikasi keteraturan yang berpola, 3. Menghubungkan kategori dengan kerangka analitis dalam literatur, mengkontekstualkan dengan kerangka kerja literatur, dan 4. Menampilkan data yaitu dengan menampilkan temuan dalam tabel, bagan, gambar, dan diagram; membandingkan kasus; membandingkan dengan kasus standar.

\section{HASIL PENELITIAN}

\section{Strategi Perusahaan Memasuki Pasar Internasional}

Pasar internasional sangatlah menarik untuk dimasuki, oleh karena itu banyak perusahaan entrepreneur yang berekspansi memasuki pasar internasional oleh karena itu UD. Budi Luhur memilih untuk juga memasarkan produknya pada pasar internasional. Terdapat berbagai alasan bagi UD. Budi Luhur dalam memasuki pasar internasional. Alasan tersebut diantaranya untuk mendapatkan pasar yang luas dan memperoleh pendapatkan yang lebih besar. China merupakan pasar utama tujuan ekspor UD. Budi Luhur. Pasar internasional memiliki banyak pilihan target pasar. Dengan perusahaan entrepreneur berhasil memasuki pasar internasional maka hal tersebut menjadi keuntungan lebih apabila pasar yang satu sedang turun, maka pasar lain dapat menutupi kekurangan tersebut. Hal ini sejalan dengan penelitian yang telah dilakukan pada UKM di Lombok oleh Prastyoko (2016). 
Produk djembe merupakan produk utama ekspor dari UD. Budi Luhur dan merupakan produk ekspor unggulan di Kota Blitar, menurut Bapak Junariadi, Kepala bagian UKM, Dinas Koperasi dan UKM Kota Blitar, produk djembe dari UKM di Kota Blitar hanya 5\% dipasarkan di dalam negeri, dan 95\% di ekspor. UD. Budi Luhur melakukan ekspor ke beberapa negara seperti Tunisia, Korea, Timur Tengah, Swiss, Australia, Singapore dan China. China merupakan negara tujuan ekspor UD. Budi Luhur dengan volume penjualan tertinggi.

Penjualan ekspor ke buyers luar negeri terdiri dari produk djembe dengan berbagai ukuran dan desain, serta yang dipesan sesuai dengan kriteria produk oleh buyers dari luar negeri. Buyers memiliki kriteria pemesanan produk sesuai dengan keinginan, karena biasanya buyers menjual kembali produk atau digunakan untuk keperluan bisnis lainnya. Salah satu perkembangan. paling signifikan dalam praktik dunia usaha dewasa ini adalah pertumbuhan pesat aktivitas internasional. Ekspor, investasi langsung asing dan penentuan sumber pengadaan produk dan komponen di luar negeri telah merebak secara dramatis.

Dalam situasi seperti itu UD. Budi Luhur memasuki pasar internasional untuk mencari sumber komponen secara lebih efektif dan memasuki pasar produk yang bertumbuh yang lebih menjanjikan dibandingkan pasar domestik dan didukung oleh berlakunya perdagangan bebas, hal ini sejalan dengan penelitian yang telah dilakukan oleh Darmayani (2014) yang meneliti mengenai strategi pemasaran UKM di Lombok untuk meningkatkan nilai ekspor. Darmayani (2014) mengatakan bahwa kekuatan terbesar perusahaan terletak pada fokus pemasaran ekspor perusahaan, dan peluang terbesar perusahaan adalah munculnya perdagangan bebas yang dapat mempermudah akses ke pasar internasional

Strategi Kewirausahaan (Strategic Entrepreneurship) UD. Budi Luhur dalam Memasarkan Produk Hitt et al. (2001) menjelaskan bahwa strategi entrepreneur adalah sebuah tindakan kewirausahaan dengan menggunakan perspektif sebuah strategi. Venkataraman dan Sarasvathy dalam Hitt, at al (2001) secara sederhana menjelaskan strategi entrepreneur adalah sebuah integrasi dari kewirausahaan dalam arti tindakan melihat kesempatan dan strategi (melihat keuntungan) perspektif dalam mengembangkan dan mengambil tindakan yang 
dirancang untuk menciptakan sebuah kekayaan. Adanya tindakan dari kewirausahaan akan menyebabkan integrasi entrepreneurship dan strategi manajemen terjadi secara alami. UD. Budi Luhur pada saat memulai start up perusahaan entrepreneur,

Disini peran pemerintah diperlukan UD. Budi Luhur dalam mendorong keberhasilam perusahaan dalam memperoleh akses untuk memperluas jaringan pemasarannya. Pemerintah memberikan kemudahan dan kecepatan dalam memperoleh informasi pasar kepada UKM sehingga memiliki kemudahan dan kecepatan dalam mengkomunikasikan usahanya kepada konsumen secara luas baik di dalam maupun di luar negeri. Komunikasi dalam menjalankan bisnis bagi Dinas Koperasi dan UKM Daerah dan UD. Budi Luhur adalah sangat penting, karena dengan komunikasi akan membuat ikatan emosional yang kuat dengan pelanggan yang sudah ada, juga memungkinkan datangnya pelanggan baru.

Penerapan Strategi Kewirausahaan (Strategic Entrepreneurship) Berdasarkan hasil wawancara dan data yang didapat, dapat diketahui beberapa alternatif strategi mempertahankan entrepreneurial strategies yang dapat dilakukan perusahaan hasil dari analisis tersebut adalah sebagai berikut :

a. Strategi Perluasan Pasar Ekspor Sebagai perusahaan yang bergerak dalam bidang kerajinan kriya/handycraft dengan memilih fokus memasarkan produknya di pasar internasional melalui ekspor perusahaan harus melakukan pengbembangan pangsa pasar ekspor yang lebih luas dengan memanfaatkan perdagangan bebas yang dapat mempermudah akses ke pasar internasional. Dengan memperluas ruang lingkup pemasaran dapat mengantisipasi kejenuhan dalam satu pasar atau negara tertentu dan diikuti dengan peningkatan kapasitas produksi perusahaan. Untuk perusahaan entrepreneur dapat tumbuh berkembang dengan memasuki dan mempertahankan pasar, perusahaan harus mampu melihat peluang dan menetapkan strategi. Saat ini UD. Budi Luhur telah memiliki hubungan yang baik dengan buyers dari China dan beberapa negara lain.

b. Mempertahankan Networking Semakin luas jaringan atau networking dari sebuah perusahaan maka perusahaan semakin kuat dalam menghadapi pasar 
internasional. Perusahaan harus menjalin hubungan baik dengan buyers dengan sering berkomunikasi dengan para buyers agar perusahaan dapat mengetahui apa yang menjadi keinginan buyers. Servis digunakan UD. Budi Luhur untuk mengikat para buyers yang menjadi mitra dari perusahaan agar tetap loyal. Servis digunakan perusahaan sejak awal start up dengan selalu menerima dengan baik keluhan dari para buyers.

c. Melakukan Kerjasama dengan Usaha Sejenis Perusahaan perlu mengimplementasikan strategi yang berpotensi untuk meningkatkan pasar ekspor yang berpotensi dalam jangka panjang, dengan melakukan kerjasama dengan pelaku usaha yang sejenis perusahaan dapat mengerjalan pesanan dari buyers tepat waktu dan meningkatkan produksi dan penjualan.

d. Strategi Inovasi Inovasi perusahaan dengan menawarkan berbagai desain untuk produk djembe. Berbagai desain produk yang menarik dan unik menyebabkan perusahaan mampu mempertahankan buyers. Selain desain produk, kualitas produk semakin ditingkatkan oleh perusahaan. Produk yang berkualitas akan menjadi nilai lebih bagi relasi atau buyers sehingga relasi akan semakin loyal dengan perusahaan. Dari strategi yang telah dipaparkan oleh pelaku bisnis dari UD. Budi Luhur, perusahaan telah berhasil melakukan inovasi yang baik. Inovasi adalah jantung dari pola pikir entrepreneurship/kewirausahaan (Peng, 2009:130). Inovasi tidak hanya berupa teknologi tetapi cara berpikir substansial dan merupakan jalan baru dalam bisnis, sehingga inovasi ini disebut inovasi perusahaan. Pelaku bisnis di UKM cenderung lebih inovatif dan mengambil risiko dibandingkan dengan perusahaan-perusahaan besar (Peng, 2009:131). Maka dengan strategi-strategi tersebut perusahaan dapat bertahan di pasar internasional.

\section{KESIMPULAN}

Dari penyajian data dan pembahasan yang sudah dijelaskan terkait strategic entrepreneurship pada UD. Budi Luhur yang sudah disampaikan pada bab sebelumnya, maka dapat ditarik kesimpulan bahwa: 
1. Strategi UD. Budi Luhur dalam memasuki pasar internasional berupa ekspor. Ekspor merupakan langkah yang tidak terlalu rumit dan tidak berisiko tinggi, apalagi bagi perusahaan entrepreneur yang baru akan memasuki pasar ekspor. China merupakan pasar utama tujuan ekspor UD. Budi Luhur. Pasar internasional memiliki banyak pilihan target pasar. Dengan perusahaan entrepreneur berhasil memasuki pasar internasional maka menjadi hal tersebut menjadi keuntungan lebih apabila pasar yang satu sedang turun, maka pasar lain dapat menutupi kekurangan tersebut.

2. UD. Budi Luhur memulai start up perusahaan dengan cara membuka artshop di Bali karena melihat permintaan djembe dari Bali kian meningkat. Dengan memiliki artshop di Bali semakin menambah fasilitas yang dimiliki, memberikan peluang untuk mendapatkan buyer baru, berawal dari hal tersebut Bapak H. Tohari dapat menciptakan good relationship dengan para buyers atau relasi.

3. Dari lima strategi kewirausahaan atau five entrepreneurials strategies yang dikemukakan Peng (2009:130) UD. Budi Luhur menerapkan empat strategi dalam memaksimalkan penjualan dan meningkatkan volume penjualan ekspor sesuai dengan tinjauan teori sebelumnya yaitu:

a. Growth Ketika mendapatkan pesanan djembe dari Bali dengan jumlah yang banyak, beliau langsung menyadari bahwa mendirikan artshop di Bali merupakan peluang bagi UD. Budi Luhur untuk mengembangkan pasar sehingga menambah penjualan dan laba.

b. Innovation Inovasi pada produk menjadi pilihan bagi UD. Budi Luhur. Perusahaan memilih strategi pengembangan produk djembe dengan berbagai ukuran dan desain. Produk yang diciptakan dapat dikatakan fleksibel dalam mengembangkan produk dan inovasi karena produk dihasilkan melalui permintaan buyers serta home industri pengrajin djembe yang menciptakan desain produk sesuai dengan karya seni mereka.

c. Network Keberhasilan UD. Budi Luhur dalam memasuki pasar internasional didapatkan dari penerapan network strategy yang baik yang dilakukan oleh Bapak H. Tohari selaku pemilik perusahaan entrepreneur. 
UD. Budi Luhur mampu menciptakan good relationship dengan para relasi dan mampu membentuk jaringan yang menguntungkan.

d. Harvest/exit UD. Budi Luhur berhasil menerapkan startegi ini secara terstruktur dengan tidak menjalankan usahanya secara individu melainkan bekerja sama dengan pengrajin djembe formal dan non formal di Kelurahan Tanggung dalam memenuhi permintaan pasar agar pengerjaan pesanan produk tepat waktu serta pengiriman produk untuk sampai ke negara buyers sesuai dengan waktu yang telah ditetapkan pada saat pemesanan.

\section{DAFTAR PUSTAKA}

Creswell, Jhon W. 2015. Research Design: Qualitative, Quantitative, Mixed Methods Approaches. Singapore: SAGE

Darmayani, Ade Ismi. 2014. Strategi Pemasaran Kerajinan Buah Kering untuk Meningkatkan Nilai Ekspor pada UD Indo Nature, Lombok-NTB. Malang: Universitas Brawijaya

Hitt, Michael A., R. Duanne Ireland, S. Michael Camp and Donald L. Sexton. 2001. Strategic Entrepreneurship: Creating a New Mindset. United States: Wiley Blackwell Hitt, Michael A., Ireland, S., Michael Camp, and Donald L. Sexton. 2001. Guest editors introduction the special issue strategic entrepreneurship: entrepreneurial strategies for wealth creation. Strategic Managemet Journal. 2(2). 479491

Kotler, Philip dan Keller, Kevin Lane. 2009. Manajemen Pemasaran: Edisi Tiga Belas Jilid 1. Dialihbahasakan oleh Bob Sabran, M.M. Jakarta: Erlangga

Kristiyanti, Mariyana. 2014. Peran Strategis Usaha Kecil Menengah (UKM) dalam Pembangunan Nasional. Jakarta: Majalah Ilmiah Informatika Vol. 3 No.1 (Januari 2012)

Peng, Mike W. 2009. Global Strategy. Second Edition. Canada: South-Western CENGAGE Learning 